\title{
Pengembangan Kuesioner Peran Suami dalam Mempengaruhi Keputusan Ibu Hamil untuk Mengkonsumsi Tablet Suplementasi Besi di Banjarmasin
}

\author{
Sudjatmiko Setyobudihono ${ }^{1}$ \\ Program Studi Keperawatan STIKES Cahaya Bangsa, Banjarmasin \\ Ermina Istiqomah \\ Prodi Psikologi Fak. Kedokteran Universitas Lambung Mangkurat, Banjarbaru
}

\begin{abstract}
Direct orders of the husband is generally a matter that can not be rejected by a pregnant woman. There are no validated questionnaires based on the understanding of the husband's role in affecting pregnant women. Based on previous research we managed to develop a questionnaire that describes the main themes of concern to pregnant women in order to follow her husband to consume tablets that affect iron supplementation. This study describes the contents of the validation stage for the development of a new questionnaire, which will be the main subject for a subsequent psychometric analysis. The initial questionnaire consisting of 40 items tested the validity of the content to include 10 experts in the fields of nursing, public health and psychology. Using the content validity ratio and content validity index produced 27 items that have a value above 0.78. 5 pregnant women who participate in the program suplemenasi iron tablet consumption included in a cognitive interview session after modifications questionnaire was conducted.
\end{abstract}

Keywords: iron tablets; husband; validity of the content; questionnaire

\begin{abstract}
Abstrak: Perintah langsung dari suami pada umumnya merupakan hal yang tidak dapat ditolak oleh seorang ibu hamil. Tidak ada kuesioner tervalidasi berdasar pemahaman peran suami dalam mempengaruhi ibu hamil. Berdasarkan penelitian terdahulu kami berhasil mengembangkan kuesioner yang menggambarkan tema utama yang menjadi perhatian ibu hamil dalam mengikuti perintah suami yang mempengaruhinya untuk mengkonsumsi tablet suplementasi besi. Penelitian ini menjabarkan tahapan validasi isi bagi pengembangan kuesioner baru, yang akan menjadi subyek utama bagi sebuah analisis psikometrik selanjutnya. Kuesioner awal yang terdiri dari 40 item yang diuji validitas isi dengan menyertakan 10 orang ahli di bidang keperawatan, kesehatan masyarakat dan psikologi. Menggunakan rasio validitas isi dan indek validitas isi menghasilkan 27 item yang memiliki nilai diatas 0,78 . 5 orang ibu hamil yang ikut program konsumsi tablet suplemenasi besi diikut sertakan dalam sebuah sesi wawancara kognitif setelah modifikasi kuesioner dilakukan.
\end{abstract}

Kata kunci: tablet suplementasi besi; suami; validitas isi; kuesioner

Korespondensi tentang artikel ini dapat dialamatkan kepada Sudjatmiko Setyobudihono melalui e-mail: Sudjatmikosetobudihono16@gmail.com; atau kepada Ermina Istiqomah melalui e-mail: erminaistiqomah06@yahoo.com. 
Suami dapat dipahami merupakan figur sentral dari seorang ibu hamil (isteri), dalam usaha mempertahankan kedamaian dan menghindari setiap konflik dalam kehidupan selama kehamilan yang hingga saat ini masih dipegang teguh oleh sebagian besar masyarakat di Indonesia (Ford dan Parker, 2008; Woodward, 2011). Di Indonesia seorang ibu akan mendahulukan pendapat suami dan ayahnya sebelum pendapat mereka sendiri (Prasilowati, 2000). Dalam sebuah penelitian di Indonesia diketahui bahwa suami memiliki peran lebih kuat bagi ibu hamil dalam melakukan pemeriksaan Ante Natal Care (ANC) secara teratur dibandingkan peran orang tua (Hafidz, 2007). Oleh karena itu peran suami penting untuk diperhatikan terkait pengaruhnya dalam proses pembuatan keputusan seorang ibu hamil.

Pemberian tablet tambah darah merupakan cara yang efektif untuk penanganan dan pencegahan anemia akibat defisiensi besi. Peraturan pemerintah menganjurkan ibu hamil untuk mengkonsumsi tablet suplementasi besi setiap hari selama masa kehamilannya atau minimal 90 (sembilan puluh) (Permenkes RI no. 88 tahun 2014). Hal ini perlu dilakukan pada ibu hamil karena risiko ibu hamil untuk mendapat anemia gizi besi lebih besar dibandingkan dengan keadaan lain (Ramakrishnan, 2001). Penggunaan bentuk tablet suplementasi besi dalam program penanggulangan anemia gizi besi masih dipandang sebagai salah satu cara terbaik dan efektif dalam sebuah program (Beard, 2000; Cavali-Sforza, 2005; Zhou et al., 2006; Agarwal et al., 2008).

Praktik pemberian tablet suplementasi zat besi sebagai langkah penanggulangan dan pencehagan anemia telah dilaksanakan tetapi terindikasi adanya bukti bahwa ibu hamil tidak memakannya secara kontinyu (Johnson dan Graham, 2011). Tingginya klaim pemberian tablet $\mathrm{Fe}$ pada ibu hamil tidak diikuti dengan tingginya konsumsi tablet Fe. Klaim cakupan ibu hamil yang mendapat tablet suplementasi besi di Provinsi Kalimantan Selatan tercatat $79,8 \%$ perempuan usia 10-59 tahun yang hamil telah mendapat atau membeli tablet $\mathrm{Fe}$ tetapi hanya $21,2 \%$ ibu hamil yang melaporkan minum tablet Fe lebih dari 90 hari (Riskesdas, 2010).

Dalam sebuah penelitian yang bertujuan meneliti hubungan antara norma subyeksif dan sikap terhadap niat ibu hamil dalam mengkonsumsi tablet suplementasi besi diketahui bahwa norma subyektif merupakan determinan yang lebih kuat lebih kuat dibandingkan dengan sikap terhadap niat ibu hamil dalam mengkonsumsi tablet suplementasi besi (Setyobudihono dan Istiqomah, 2014). Penelitian kualitatif yang bertujuan memahami keputusan suami dalam mempengaruhi keputusan ibu hamil untuk mengkonsumsi tablet suplementasi besi menghasilkan pemahaman akan adanya 4 tema yang merupakan fokus bagi ibu hamil untuk dipertimbangkan dalam membuat keputusan untuk mengkonsumsi tablet suplementasi besi. tema-tema tersebut adalah: pemberian izin dari suami, patuh pada keputusan suami karena ajaran agama, kompromi dengan keputusan suami dan patuh pada suami karena kedudukan istimewa suami dalam keluarga (Setyobudihono dan Istiqomah, 2015). Dengan demikian tema peran suami dalam mempengaruhi keputusan ibu hamil dalam mengkonsumsi tablet suplementasi besi sebagai dasar bagi pembuatan kuesioner sudah didapati.

Tujuan dari penelitian ini adalah untuk melakukan tahap pertama pengembangan kuesioner peran suami dalam mempengaruhi keputusan ibu hamil untuk mengkonsumsi tablet suplementasi besi.

\section{Metode}

Penilaian kelaikan etik studi ini dilakukan oleh Komisi Etik Penelitian LPPM Universitas Airlangga Nomor: 27-1114/UN3.14/PPd/2013 tanggal 27 September 2013.

Penelitian ini merupakan langkah awal yang penting dalam memberikan bukti validitas isi, yaitu sejauh mana kuesioner dapat mengukur konstruk dimaksudkan dan telah sesuai untuk tujuan penggunaannya. 
Tahapan-tahapan yang digunakan dalam penelitian dijabarkan sebagai berikut:

\section{Pengumpulan Item Pernyataan}

Kuesioner awal disusun berdasarkan hasil penelitian terdahulu mengenai faktor peran suami dalam mempengaruhi ibu hamil dalam mengkonsumsi suplementasi besi. Peneliti dan 2 orang ahli dalam bidang kebidanan dan promosi kesehatan ibu dan anak, menjabarkan kuesioner dalam 40 item. Item-item tersebut terdiri dari masing-masing 10 item tiap faktor peran suami. Panduan menyusun item-item dalam kuesioner adalah 4 dimensi kekuatan sosial bagi ibu hamil dalam mengkonsumsi tablet suplementasi besi (Setyobudihono dan Istiqomah, 2015), yaitu:

a Faktor pemberian izin dari pemegang kekuatan

Orang akan taat kepada pemegang kekuatan sedang dalam kedudukan superior dalam suatu struktur sosial formal dan informal (Raven, 2008). Seseorang ibu hamil (isteri) akan melakukan sesuatu hal yang berhubungan dengan keyakinan tentang izin yang diberikan oleh suami dan mendahulukan izin yang diberikan oleh suami dibandingkan orang lain. Keputusan untuk meneruskan atau menghentikan program suplementasi besi tidak saja diambil oleh ibu hamil tetapi melibatkan izin dari pemegang kekuatan yang sedang memiliki kekuatan untuk mempengaruhi.

$b$ Faktor patuh pada pemegang kekuatan karena ajaran agama

Seorang ibu hamil (isteri) akan menghargai setiap keputusan yang berbeda dan memperlakukan dengan hormat seseorang dengan posisi yang lebih kuat karena keyakinan mereka atas ajaran agama (Islam). Hal tersebut merupakan cara agar terdapat perasaan nyaman dan damai ketika akan melakukan sesuatu hal, terutama yang berhubungan dengan perawatan kesehatan. c Faktor kompromi dengan keputusan pemegang kekuatan

Seorang ibu hamil (isteri) akan mengandalkan keputusan bersama bagi setiap tindakan dan percaya dengan kehendak bersama dalam pembuatan keputusan agar mencapai segala tujuan yang diinginkan. Hal tersebut dilakukan sebagai wujud kompromi dengan lingkungan agar terjaga stabilitas dan kedamaian.

d Faktor patuh karena pemegang kekuatan memiliki kedudukan istimewa

Seorang ibu hamil (isteri) akan menuruti perintah dari suami karena memiliki pengaruh, sadar bahwa ada pemegang kekuatan berpengaruh memiliki hak untuk memerintah, dan menyesuaikan diri dengan keinginan pemegang kekuatan karena memiliki pengaruh karena kedudukan sebagai seorang suami. Hal tersebut dilakukan karena membutuhkan struktur yang jelas, perintah dari otoritas yang berwenang untuk bergerak dengan cara taat pada peraturan yang ada.

\section{Pilihan Respon Item}

Keseluruhan item bersifat favorable. Kuesioner disusun menggunakan skala Likert dengan lima pilihan yang tersebar dari rentang skor $1=$ sangat tidak setuju sampai skor $5=$ sangat setuju.

\section{Ulasan Para Ahli}

Untuk menjaga validitas kuesioner maka dilakukan langkah validitas isi yang dapat diperoleh melalui penilaian ahli. Ahli melakukan penilaian terhadap rancangan kuesioner untuk menjamin adanya validitas isi. Penelitian ini merekrut 10 ahli dengan berbagai latar belakang ilmu yang relevan. Literatur menyarankan minimal 5 dan maksimal 10-20 ahli untuk melakukan penilaian isi (Slocumb dan Cole, 1991; Polit, Beck dan Owen, 2007). Para ahli adalah 6 orang dosen dan praktisi keperawatan maternitas, komunitas, jiwa, dan gawat darurat, 3 orang dosen dan praktisi kesehatan 
masyarakat promosi kesehatan, manajemen, dan gizi serta 1 orang dosen dan praktisi psikologi yang bekerja di Kalimantan Selatan.

Pertanyaan yang disusun menjadi subkelompok gejala di bawah judul: pemberian izin dari pemegang kekuatan, patuh pada pemegang kekuatan karena ajaran agama, kompromi dengan keputusan pemegang kekuatan, patuh karena pemegang kekuatan memiliki kedudukan istimewa. Dari 40 item yang termasuk dalam review konten kuesioner, 10 item berhubungan dengan pemberian izin dari pemegang kekuatan, 10 item patuh pada pemegang kekuatan karena ajaran agama, 10 item untuk kompromi dengan keputusan pemegang kekuatan, dan 10 item untuk patuh karena pemegang kekuatan memiliki kedudukan istimewa. Para ahli diminta untuk menilai relevansi setiap item pada skala empat poin, yaitu $1=$ tidak relevan, $2=$ kurang relevan, $3=$ cukup relevan dan $4=$ relevan. Dalam formulir untuk para ahli juga disertakan ruang bagi komentar bebas serta masukkan atas rancangan kuesioner tersebut. Pengolahan data validasi isi menggunakan Content Validity Ratio (CVR) dan Content Validity Index (CVI).

Lawshe (1975) mengusulkan rasio validitas isi (CVR) untuk mengukur derajat kesepakatan para ahli dari satu item dan yang dapat mengekspresikan tingkat validitas konten melalui indikator tunggal yang berkisar dari -1 sampai 1. Dalam penelitian ini untuk menghitung CVR untuk setiap item adalah item yang dinilai ahli 3 atau 4 ( $3=$ item perlu sedikit revisi, $4=$ item yang relevan).

Setelah mengidentifikasi setiap sub pertanyaan instrumen angket dengan menggunakan CVR, maka selanjutnya dilakukan Indek validitas isi (CVI). CVI digunakan untuk menghitung keseluruihan jumlah sub pertanyaan. CVI dihitung untuk setiap item dan kuesioner secara keseluruhan (Lawshe, 1975). CVI didefinisikan sebagai proporsi ahli yang dinilai pertanyaan yang relevan dan indeks kesepakatan antar-penilai. Untuk menghitung CVI untuk setiap item, jumlah item yang dinilai ahli 3 atau 4 (3= item perlu sedikit revisi, $4=$ item yang relevan) dibagi dengan jumlah sub pertanyaan
(Lawshe, 1975; Rico et al., 2012). Literatur merekomendasikan nilai CVI 0,78 untuk pertanyaan yang akan dianggap sebagai relevan (Rico et al., 2012; Borges et al., 2013). Item dengan hasil lebih rendah dapat dipertimbangkan untuk direvisi atau dihapus.

Hasil penilaian ahli di kumpulkan menggunakan suatu formulir penilaian isi kuesioner. Pertanyaan disusun berdasarkan faktor peran suami dalam mempengaruhi ibu hamil dalam mengkonsumsi suplementasi besi yaitu izin suami, suami sebagai imam, kompromi dalam keputusan dan kedudukan suami. Selama proses validitas isi, ahli menggunakan definisi domain ukur yang disusun sebagai dasar untuk menilai sejauh mana item mereprentasikan domain ukur yang dimaksudkan. Tidak ada insentif ditawarkan bagi para partisipan.

\section{Wawancara Evaluasi Kuesioner}

Wawancara kognitif adalah metode yang direkomendasikan pra-pengujian atau evaluasi kuesioner dan fokus pada proses kognitif dari responden (Willis dan Artino, 2013). Wawancara dilakukan kepada ibu hamil yang melakukan pernikahan resmi dan memiliki suami yang masih hidup. Setiap ibu hamil diminta membaca item dan dimintakan pendapat tentang format respon, kerangka waktu, kejelasan pertanyaan dan tata letak umum. Wawancara dilakukan kepada 5 orang ibu hamil dari beberapa puskesmas dan klinik kebidanan yang ada di sekitar Kota Banjarmasin. Tidak ada insentif ditawarkan bagi para partisipan.

\section{Hasil}

\section{Ulasan Para Ahli Tentang Isi Kuesioner}

10 orang ahli dengan latar belakang kesehatan dan psikologi ikut serta dalam tahapan pengembangan kuesioner. Para ahli yang terlibat terdiri dari: 6 orang dosen dan praktisi keperawatan maternitas, komunitas, jiwa, dan gawat darurat, 3 orang dosen dan praktisi kesehatan masyarakat promosi kesehatan, manajemen, dan gizi serta 1 orang 
dosen dan praktisi psikologi yang bekerja di Kalimantan Selatan.

Hasil ulasan ahli terhadap 40 item pernyataan yang terbagi dalam 4 subjudul tentang peran suami dalam mempengaruhi keputusan ibu dalam mengkonsumsi tablet suplementasi besi menunjukkan bahwa terdapat 13 item yang dipertimbangkan untuk dibuang, karena memiliki nilai CVR dibawah 0,5, masing-masing adalah faktor izin suami terdapat 4 item pertanyaan yang di rekomendasikan untuk dibuang, faktor suami sebagai imam terdapat 3 item pertanyaan yang direkomendasikan untuk dibuang, faktor kompromi dalam keputusan terdapat 3 item pertanyaan yang direkomendasikan untuk dibuang, faktor kedudukan suami terdapat 3 item pertanyaan yang direkomendasikan untuk dibuang dan terdapat 2 item (K8 dan P7) yang dipertimbangkan untuk direvisi terlebih dahulu sebelum dikembalikan, karena memiliki nilai CVI antara 0,34-0,78. Berikut dalam Tabel 1 adalah nilai indek validitas isi per item dan rasio validitas isi.

Selanjutnya untuk 2 item direvisi kembali sebelum dikembalikan. Berikut pada Tabel 2 modifikasi item revisi.

Tabel 1. Hasil ulasan isi kuesioner

\begin{tabular}{|c|c|c|c|c|c|c|}
\hline No & Item & Jum & Kat & $\%$ & CVI & CVR \\
\hline \multicolumn{7}{|c|}{ Pemberian izin dari pemegang kekuatan } \\
\hline 1 & $\begin{array}{l}\text { Izin suami adalah sangat penting untuk mulai menjalankan program } \\
\text { pengobatan }(\mathrm{S} 1)\end{array}$ & 36 & 4 & 86,9 & 0,99 & 0,99 \\
\hline 2 & $\begin{array}{l}\text { Saya merasa terhormat dalam mengikuti suatu program pengobatan } \\
\text { karena sesuai dengan izin suami(S2) }\end{array}$ & 35 & 4 & 83,3 & 0,99 & 0,99 \\
\hline 3 & $\begin{array}{l}\text { Dalam menjalankan program kesehatan akan lebih baik jika mendapat } \\
\text { (S3) }\end{array}$ & 36 & 4 & 86,7 & 0,99 & 0,99 \\
\hline 4 & Saya yakin akan mendapat hukuman jika saya melanggar izin (S4) & 21 & 2 & 36,7 & 0,6 & $-0,6$ \\
\hline 5 & $\begin{array}{l}\text { Saya akan mendapat banyak masalah dari suami jika saya melanggar } \\
\text { izinnya. (S5) }\end{array}$ & 20 & 2 & 33,3 & 0,4 & $-0,4$ \\
\hline 6 & $\begin{array}{l}\text { Saya merasa damai dalam menjalani program pengobatan karena saya } \\
\text { yakin dengan izin dari suami }(\mathrm{S} 6)\end{array}$ & 34 & 4 & 80 & 0,6 & 0,6 \\
\hline 7 & $\begin{array}{l}\text { Mematuhi izin dari suami saya perlukan untuk lebih mendorong saya } \\
\text { menjalankan program kesehatan (S7) }\end{array}$ & 34 & 4 & 80 & 0,6 & 0,6 \\
\hline 8 & $\begin{array}{l}\text { Dalam menjalankan program kesehatan izin suami masih diperlukan } \\
\text { walaupun saya bebas dalam membuat keputusan (S8) }\end{array}$ & 37 & 4 & 90 & 0,8 & 0,8 \\
\hline 9 & $\begin{array}{l}\text { Saya sadar bahwa ada seseorang yang memiliki hak untuk memberi izin } \\
\text { dalam membuat keputusan di suatu program pengobatan (S9) }\end{array}$ & 17 & 1 & 23,3 & 0,6 & $-0,6$ \\
\hline 10 & $\begin{array}{l}\text { Saya sadar bahwa segala keputusan yang terkait dengan program } \\
\text { pengobatan harus melibatkan izin suami (S10) }\end{array}$ & 21 & 2 & 36,7 & 0,4 & $-0,4$ \\
\hline \multicolumn{7}{|c|}{ Patuh pada pemegang kekuatan karena ajaran agama } \\
\hline 11 & $\begin{array}{l}\text { Suami adalah imam (kepala) keluarga yang keputusannya dalam } \\
\text { program kesehatan sebaiknya saya ikuti (Y1) }\end{array}$ & 39 & 4 & 96,7 & 0,99 & 0,99 \\
\hline 12 & $\begin{array}{l}\text { Saya menjalankan semua program pengobatan berdasarkan informasi } \\
\text { yang diberikan oleh suami (Y2) }\end{array}$ & 18 & 2 & 26,7 & 0,6 & $-0,6$ \\
\hline 13 & $\begin{array}{l}\text { Walaupun saya bebas membuat keputusan tetapi saya sadar bahwa } \\
\text { agama saya mengharuskan saya untuk selalu memahami keputusan } \\
\text { suami (Y3) }\end{array}$ & 34 & 4 & 80 & 0,6 & 0,6 \\
\hline 14 & $\begin{array}{l}\text { Mematuhi keputusan suami sebagai imam (kepala) keluarga adalah baik } \\
\text { untuk meneruskan program kesehatan (Y4) }\end{array}$ & 35 & 4 & 83,3 & 0,8 & 0,8 \\
\hline 15 & $\begin{array}{l}\text { Dalam membuat keputusan mengikuti suatu program kesehatan akan } \\
\text { nyaman jika yakin pada peran suami sebagai imam (Y5) }\end{array}$ & 35 & 4 & 83,3 & 0,6 & 0,6 \\
\hline 16 & $\begin{array}{l}\text { Saya merasa damai dalam menjalani program pengobatan karena saya } \\
\text { yakin dengan suami sebagai imam (kepala) keluarga (Y6) }\end{array}$ & 34 & 4 & 80 & 0,8 & 0,8 \\
\hline 17 & $\begin{array}{l}\text { Kedudukan suami sebagai imam memberikan ketentraman bagi saya } \\
\text { dalam menjalani suatu program pengobatan. (Y7) }\end{array}$ & 36 & 4 & 86,7 & 0,8 & 0,8 \\
\hline
\end{tabular}




\begin{tabular}{|c|c|c|c|c|c|c|}
\hline No & Item & Jum & Kat & $\%$ & CVI & CVR \\
\hline 18 & $\begin{array}{l}\text { Ketika saya menghadapi kesulitan dalam menjalankan program } \\
\text { kesehatan maka keputusan suami yang pertama kali saya } \\
\text { pertimbangkan.(Y8) }\end{array}$ & 37 & 4 & 90 & 0,99 & 1 \\
\hline 19 & $\begin{array}{l}\text { Ketika saya mendapatkan masalah dalam menjalankan suatu program } \\
\text { pengobatan, maka saya sangat tergantung dengan suami. (Y9) }\end{array}$ & 22 & 2 & 40 & 0,4 & $-0,4$ \\
\hline 20 & $\begin{array}{l}\text { Segala keputusan saya buat dalam menjalankan suatu program } \\
\text { pengobatan adalah sesuai dengan segala informasi yang saya dapat } \\
\text { suami. (Y10) }\end{array}$ & 19 & 2 & 30 & 0,6 & $-0,6$ \\
\hline \multicolumn{7}{|c|}{ Kompromi dengan keputusan pemegang kekuatan } \\
\hline 21 & $\begin{array}{l}\text { Menyesuaikan diri dengan keputusan suami baik untuk menjalankan } \\
\text { suatu program kesehatan (K1) }\end{array}$ & 36 & 4 & 86,7 & 0,8 & 0,8 \\
\hline 22 & $\begin{array}{l}\text { Keputusan bersama suami adalah keputusan terbaik dalam menjalankan } \\
\text { program kesehatan.(K2) }\end{array}$ & 37 & 4 & 90 & 0,99 & 1 \\
\hline 23 & $\begin{array}{l}\text { Saya yakin bahwa setiap keputusan yang saya ambil sudah sesuai dengan } \\
\text { keputusan suami (K3) }\end{array}$ & 20 & 2 & 33,3 & 0,6 & $-0,6$ \\
\hline 24 & $\begin{array}{l}\text { Penting untuk menyesuaikan diri dengan keputusan suami dalam } \\
\text { menjalankan suatu program pengobatan (K4) }\end{array}$ & 35 & 4 & 83,3 & 0,6 & 0,6 \\
\hline 25 & $\begin{array}{l}\text { Walaupun saya bebas membuat keputusan tetapi saya tidak akan } \\
\text { mempertanyakan semua keputusan yang dibuat oleh suami (K5) }\end{array}$ & 33 & 4 & 76,7 & 0,6 & 0,6 \\
\hline 26 & $\begin{array}{l}\text { Saya akan terus menyesuaikan diri dengan keputusan suami karena } \\
\text { memberikan kenyamanan untuk meneruskan program kesehatan yang } \\
\text { sedang saya lakukan (K6) }\end{array}$ & 35 & 4 & 83,3 & 0,8 & 0,8 \\
\hline 27 & Saya tidak keberatan jika suami berbeda pendapat dengan saya (K7) & 15 & 1 & 16,7 & 0 & -1 \\
\hline 28 & $\begin{array}{l}\text { Menyesuaikan diri dengan keputusan suami yang berbeda penting bagi } \\
\text { saya ketika membuat keputusan dalam suatu program pengobatan (K8) }\end{array}$ & 33 & 4 & 76,7 & 0,4 & 0,4 \\
\hline 29 & $\begin{array}{l}\text { Walaupun suami memberikan kebebasan menjalankan program } \\
\text { kesehatan, tetapi saya tidak keberatan untuk berkompromi dengan } \\
\text { keputusan suami (K9) }\end{array}$ & 33 & 4 & 76,7 & 0,8 & 0,8 \\
\hline 30 & $\begin{array}{l}\text { Keputusan yang saya ambil ketika menjalani program pengobatan adalah } \\
\text { suatu rangkuman dari berbagai keputusan suami, termasuk keputusannya } \\
\text { yang berbeda (K10) }\end{array}$ & 19 & 2 & 30 & 0,4 & $-0,4$ \\
\hline \multicolumn{7}{|c|}{ Patuh karena pemegang kekuatan memiliki kedudukan istimewa } \\
\hline 31 & $\begin{array}{l}\text { Saya tidak keberatan ketika saya harus mengikuti pendapat suami } \\
\text { sebagai bagian kewajiban seorang isteri (P1) }\end{array}$ & 34 & 4 & 80 & 0,8 & 0,8 \\
\hline 32 & $\begin{array}{l}\text { Kedudukan suami adalah penting dalam menjalankan suatu program } \\
\text { pengobatan }(\mathrm{P} 2)\end{array}$ & 36 & 4 & 86,7 & 0,8 & 0,8 \\
\hline 33 & $\begin{array}{l}\text { Semua masalah program pengobatan akan terpecahkan dengan } \\
\text { mengandalkan kedudukan suami }(\mathrm{P} 3)\end{array}$ & 21 & 2 & 36,7 & 0,2 & $-0,2$ \\
\hline 34 & $\begin{array}{l}\text { Memperhatikan kedudukan seorang suami penting bagi saya dalam } \\
\text { menjalankan suatu program kesehatan (P4) }\end{array}$ & 34 & 4 & 80 & 0,8 & 0,8 \\
\hline 35 & $\begin{array}{l}\text { Untuk meneruskan suatu program pengobatan maka diperlukan } \\
\text { keyakinan atas kedudukan suami (P5) }\end{array}$ & 20 & 2 & 33,3 & 0,2 & $-0,2$ \\
\hline 36 & $\begin{array}{l}\text { Keputusan suami saya pandang lebih penting daripada keputusan orang } \\
\text { lain dalam menjalankan program kesehatan (P6) }\end{array}$ & 33 & 4 & 76,7 & 0,6 & 0,6 \\
\hline 37 & $\begin{array}{l}\text { Kedudukan seorang suami penting untuk selalu menjadi bahan } \\
\text { pertimbangan seorang isteri dalam mengambil keputusan (P7) }\end{array}$ & 33 & 4 & 76,7 & 0,4 & 0,4 \\
\hline 38 & $\begin{array}{l}\text { Saya sadar bahwa suami memiliki hak untuk memerintah saya dalam } \\
\text { membuat keputusan di suatu program kesehatan (P8) }\end{array}$ & 35 & 4 & 83,3 & 0,6 & 0,6 \\
\hline 39 & $\begin{array}{l}\text { Agar suatu program pengobatan berhasil maka diperlukan kepercayaan } \\
\text { pada kedudukan suami (P9) }\end{array}$ & 15 & 1 & 16,7 & 0 & -1 \\
\hline 40 & $\begin{array}{l}\text { Suami memiliki hak untuk menghentikan program kesehatan yang } \\
\text { sedang saya ikuti walaupun saya merasa tidak ada masalah (P10) }\end{array}$ & 33 & 4 & 76,7 & 0,6 & 0,6 \\
\hline
\end{tabular}


Tabel 2. Modifikasi item revisi

\begin{tabular}{|c|c|c|c|}
\hline Item asal & CVI & Modifikasi & Item final \\
\hline $\begin{array}{l}\text { Menyesuaikan diri dengan } \\
\text { keputusan suami yang berbeda } \\
\text { penting bagi saya ketika membuat } \\
\text { keputusan dalam suatu program } \\
\text { pengobatan (K8) }\end{array}$ & 0,4 & $\begin{array}{l}\text { Memindahkan kata "penting } \\
\text { bagi saya", sebagai } \\
\text { penekanan pernyataan }\end{array}$ & $\begin{array}{l}\text { Penting bagi saya untuk } \\
\text { menyesuaikan diri dengan } \\
\text { keputusan suami yang berbeda } \\
\text { ketika membuat keputusan dalam } \\
\text { suatu program pengobatan (K8) }\end{array}$ \\
\hline $\begin{array}{l}\text { Kedudukan seorang suami penting } \\
\text { untuk selalu menjadi bahan } \\
\text { pertimbangan seorang isteri dalam } \\
\text { mengambil keputusan (P7) }\end{array}$ & 0,4 & $\begin{array}{l}\text { Memindahkan kata } \\
\text { mengambil keputusan } \\
\text { keawal kalimat agar lebih } \\
\text { mudah dipahami dan } \\
\text { sebagai penekanan }\end{array}$ & $\begin{array}{l}\text { Dalam mengambil keputusan maka } \\
\text { seorang isteri perlu } \\
\text { mempertimbangkan kedudukan } \\
\text { seorang suami (P7) }\end{array}$ \\
\hline
\end{tabular}

\section{Wawancara evaluasi kuesioner}

Wawancara dilakukan kepada 5 orang ibu hamil dari beberapa puskesmas dan klinik kebidanan yang ada di sekitar Kota Banjarmasin. Tidak ditemukan format respon, kerangka waktu, kejelasan pertanyaan dan tata letak umum yang perlu diperbaiki. Dengan demikian maka kuesioner dapat dikatakan telah final. Tidak ada insentif ditawarkan.

\section{Pembahasan}

Uji validitas isi menghasilkan 27 item pernyataan setelah dilakukan penilaian oleh 10 orang ahli. 5 orang ibu hamil yang melakukan pernikahan resmi dan memiliki suami yang masih hidup dilibatkan dalam wawancara kognitif tentang format respon, kerangka waktu, kejelasan pertanyaan dan tata letak umum.

Dengan selesainya uji validitas isi maka kuesioner dapat dijadikan sebagai subyek utama bagi sebuah analisis psikometrik selanjutnya.

Item-item pernyataan yang terbentuk merupakan pengembangan dari sebuah penelitian yang berkelanjutan sehingga diharapkan kuesioner ini dapat menjadi instrumen yang baik dan dapat digunakan di tempat lain.

\section{Batasan Penelitian}

Batasan penelitian utama dari hasil penelitian adalah bahwa seluruh ibu yang terlibat dalam penelitian yang bertujuan memahami keputusan suami dalam mempengaruhi keputusan ibu hamil untuk mengkonsumsi tablet suplementasi besi adalah beragama Islam (Setyobudihono dan Istiqomah, 2015). Dengan demikian keseluruhan item pernyataan hanya menggambarkan budaya setempat yang berdasarkan pada ajaran-ajaran agama Islam.

Perlu adanya penelitian lanjut terkait peran suami berdasar budaya setempat, kebijakan lokal dan agama dalam mempengaruhi kepatuhan ibu hamil untuk mengkonsumsi tablet suplementasi besi.

\section{Simpulan}

Kuesioner peran suami dalam mempengaruhi keputusan ibu hamil untuk mengkonsumsi tablet suplementasi besi dapat digunakan dalam ilmu kesehatan masyarakat, kebidanan, keperawatan, kedokteran dan psikologi. Kuesioner akan membantu petugas kesehatan untuk memahami perilaku ibu hamil terkait besarnya peran suami dalam mempengaruhi keputusannya serta dapat merancang suatu strategi komunikasi kesehatan yang lebih efektif.

\section{Dafar Pustaka}

Agarwal, T., Kochar, G.K., Goel, S. (2008). Impact of iron supplementation on anemia during pregnancy. EthnoMedicine. 2, 149-151
Beard, J.L. (2000). Effectiveness and strategies of iron supplementation during pregnancy. The American 
Journal of Clinical Nutrition. 71, 1288-1294.

Cavalli, S.T. (2005). Effectiveness of weekly iron-folic acid supplementation to prevent and control anemia among women of reproductie age in three Asian countries: development of the master protocol and implementation plan. Nutrition review. 63, 77-80. Doi: 10.1301/nr.2005.dec.S77-S80.

Ford, M., Parker, L. (2008). Women And Work In Indonesia. Routledge. New York.

Hafidz, Effi M. (2007). Hubungan peran suami dan orang tua dengan perilaku ibu hamil dalam pelayanan antenatal dan persalinan di wilayah Puskesmas Kecamatan Sedan Kabupaten Rembang. Jurnal Promosi Kesehatan Indonesia. 2 (2): 87-97.

Johnson, W.T.D., Graham, D.Y. (2011). Diagnosis and management of iron deficiency anemia in the $21^{\text {st }}$ century. Therapeutic Advances In Gastroenterology. 4, 177-184, doi: 10.1177/1756283X11398736.

Lawshe, C.H. (1975). A Qualitative approach to content validity. Personeel Psychology. 28, 563-575.

Menterian Kesehatan Republik Indonesia. Badan Penelitian dan Pengembangan Kesehatan. (2010). Riset Kesehatan Dasar (Riskesdas) 2010. Jakarta

Menteri Kesehatan Republik Indonesia. Peraturan Menteri Kesehatan Republik Indonesia Nomor 88 Tahun 2014 Tentang Standar tablet Tambah darah Bagi Wanita Usia Subur dan Ibu Hamil.

Prasilowati, S.L. (2000). An Analysis Of Women's Education In Indonesia: Empowerment And Barriers. Thesis. International Development Studies Saint Mary's University. HalifaxCanada.
Polit, D.F., Beck, C.T., Owen, S.V. (2007). Is the CVI an acceptable indicator of content validity? Appraisal and recommendation. Res Nurs Health. 30. 459-467, doi: 10.1002/nur.20199.

Ramakrishnan, U. (2001). Nutritional Anemias. CRC Press LLC. Florida.

Rico, E.D., Dios, H.C., Ruch, W. (2012). Content validity evidences in test development: an applied perspective. International Journal of Clinical and Health Psychology. 12, 449-460.

Setyobudihono, S., Istiqomah, E. (2014). Hubungan sikap dan norma subyektif dengan niat mengkonsumsi tablet suplementasi besi pada ibu hamil di Banjarmasin. Jurnal Psikologi Teori dan Terapan. 4 (2), 111-118.

Setyobudihono, S. \& Istiqomah, E. (2015). Peranan suami dalam mempengaruhi keputusan ibu hamil untuk mengkonsumsi tablet besi. Jurnal Ecopsy. 2 (1), 31-37, ISSN: 23547197, E-ISSN: 2354-7634.

Slocumb, E.M., Cole, F.L.A. (1991). Practical approach to content validation. Appl Nurs Res. 4. 192-195, doi: 10.1016/S0897-1897(OS)800977.

Willis, G.B., Artino, A.R. (2013). What do our respondents think we're asking? Using cognitive interviewing to improve medical education surveys. Journal of Graduate Medical Education. 353-356, doi: 10.4300/JGME-D-13-00154.1.

Woodward, M. (2011) Java, Indonesia And Islam. Springer. New York.

Zhou, S.J., Gibson, R.A., Crowther, C.A., Baghurst, P., Makrides, M. (2006). Effect of iron supplementation during pregnancy on the intelligence quotient and behavior of children at 4 year of age: long-term follow-up of a randomized controlled trial. The American Journal of Clinical Nutrition. 83, 1112-1117. 